\title{
Effects of various ecological factors on the germination of two crop and pasture weed species, Vulpia bromoides and Vulpia myuros
}

\author{
Sandra Weller ${ }^{1}$, Singarayer Florentine ${ }^{1, *}$, Bhagirath S. Chauhan ${ }^{2}$, Ako Mahmood ${ }^{1}$ \\ and Arunthathy Florentine ${ }^{1}$ \\ ${ }^{1}$ Centre for Environmental Management, Faculty of Science and Technology, Federation \\ University Australia, Mount Helen, Victoria, Australia. \\ ${ }^{2}$ Centre for Crop Science, Queensland Alliance for Agriculture and Food Innovation (QAAFI), \\ The University of Queensland, Gatton, Queensland, Australia. \\ ${ }^{*}$ Corresponding author: s.florentine@federation.edu.au
}

\begin{abstract}
Vulpia species (silver grasses), including V. bromoides and V. myuros, are native to the Mediterranean, Middle East and Eurasia, but have become dispersed worldwide. These two species reduce the grazing quality of pastures, frequently co-occur and are often associated with poor-quality acidic soils. This study investigated two species, Vulpia bromoides and V. myuros. Germination trials tested the effects of seasonal temperature, light, $\mathrm{pH}$, moisture, salinity, pre-germination heat shock and smoke, and seed burial depth. Vulpia bromoides germinated well regardless of temperature or light ( $>80 \%$, all conditions), whereas $V$. myuros preferred lower temperatures and absence of light $\left(97 \%, 7 / 17^{\circ} \mathrm{C}\right.$ in 24 -h dark). Under different culture conditions, the two species germinated well across the $\mathrm{pH}$ range 4 to 10 (>85\%). Reduced moisture, pre-germination heat shock and smoke, and increased burial depth reduced germination and emergence of both species. Preventing germination of these species in pastures must begin before or during winter. Fire may be useful for control, but sufficiently high temperatures must be achieved to kill seeds. Tillage to bury seeds, prior to pasture renovation, may prevent germination of seeds.
\end{abstract}

Keywords Germination ecology, Vulpia spp., pH, salinity, moisture, heat shock and smoke, burial depth.

\section{INTRODUCTION}

Silver grasses, Vulpia spp., are winter annual $\left(\mathrm{C}_{3}\right)$ species native to Eurasia, parts of the Middle East, northern Africa, and southern and central Europe (Simon 2010). This genus is almost exclusively cleistogamous (self-pollinating), meaning that only one individual is (potentially) required to establish a population (Ainscough et al. 1986, Connor 1998). Two species, Vulpia bromoides (L.) Gray and Vulpia myuros (L.) C. C. Gmel., have become dispersed from their native ranges to the Americas, New Zealand, southern Africa, and Australia (Alfonso 2010a,
Alfonso 2010b, Popay 2017, Weber 2017). Vulpia bromoides and V. myuros were introduced into Australia soon after European settlement, most likely in ship's ballast, forage, wool or as attachments to the hair of livestock (Kloot 1982). Vulpia bromoides was possibly introduced deliberately as an ornamental species, since it is listed in a commercial seed catalogue from 1886 (Wallace 1997). These two species commonly occur together in pastures throughout New South Wales and Victoria (McIntyre \& Whalley 1990, Vere et al. 2002).

These species not only provide poor quality 
feed for livestock but also outcompete native and improved pasture species (Brown \& Rice 2000, Vere et al. 2002, Dowling et al. 2004). Additionally, the seeds degrade the quality of fleece, cause injury to lambs and calves by penetrating the skin, and may cause mouth injuries, leading to significant loss of condition. Each of these issues initiates serious animalwelfare problems and considerable economic losses for livestock producers (Dowling 1996, Matthews 2000, Vere et al. 2002). During the past few decades, these weeds have begun to generate greater adverse impact on primary production than during the foregoing 150 years, as evidenced by their continued unchecked spread within the Mediterranean climatic zone of Australia and consequent detrimental economic impact (Wallace 1997, Vere et al. 2002, Vere et al. 2003, Vere et al. 2004, Dowling et al. 2004, Tozer 2004, Loo 2005). These weeds occur in pastures, as well as mixed and minimum tillage cropping (Loo 2005). The increasing threat to agriculture caused by Vulpia species urgently requires systematic investigation of methods to reduce the economic and animal welfare damage.

The main aim of this study was to determine how various ecological influences affect the germination of $V$. bromoides and $V$. myuros. Although related, these two species may have different responses to a range of germination conditions. Seeds of both species were subjected to the same three temperature and two light regimes to find optimum conditions for germination. Different culture conditions were then used to examination of the effects of $\mathrm{pH}$, salinity, moisture, heat and exposure to smoke, and burial depth on these two species. The results obtained from this work will be used to make recommendations for the management of these two weeds and to predict their responses to changes in temperature and rainfall. A secondary aim was to provide information about whether fire could be useful as part of an integrated management approach for these two species.

\section{MATERIALS AND METHODS General seed germination protocol}

Vulpia bromoides seeds were collected from Skipton (Victoria, Australia, $37^{\circ} 43^{\prime}$ 53.56" S, $143^{\circ} 23^{\prime} 50.21^{\prime \prime}$ E) in November 2015, and Vulpia myuros seeds were collected from Werribee (Victoria, Australia, 37 49' 5.63” S, $144^{\circ} 34^{\prime}$ $58.77^{\prime \prime} \mathrm{E}$ ) in October 2015. Mature inflorescences were collected from the field and taken to the seed ecology laboratory at Federation University (Mount Helen, Victoria). The inflorescences were spread out in large, paper-lined plastic trays and dried at room temperature for one week to allow seeds to fall from the inflorescences. The seeds were cleaned and stored in amber glass jars at room temperature until germination studies commenced in 2016.

For the germination trials of temperature and light, $\mathrm{pH}$, salinity, moisture, heat and smoke, three replicates of 20 seeds were used during two separate experiments, which gave a total of six replicates for each factor being tested (120 seeds). Seeds were evenly spaced in Petri dishes (11-cm diameter) on filter paper (Whatman ${ }^{\circledR}$ No. 11 ), which was moistened with $10 \mathrm{~mL}$ of either reverse osmosis (RO) water or the appropriate treatment solution (described below). Petri dishes were sealed with Parafilm ${ }^{\circledR}$ and placed into incubators (Thermoline Scientific, Temperature and Humidity Cabinet, Model: TRISLH-4951-SD, Vol 240, Australia) fitted with cool-white fluorescent lamps, with a photosynthetic flux of $40 \mu \mathrm{m} / \mathrm{m}^{2} / \mathrm{s}$. Seeds were monitored for 30 days in all trials from the date they were placed into the incubator. Seeds were assessed as 'germinated' if the radicle had emerged by $2 \mathrm{~mm}$, counted, and removed from the Petri dishes. Additional RO water or solution was added to the seeds, as required, throughout the monitoring period.

\section{Temperature and light}

To determine the optimum temperature range for germination each of these Vulpia species, three temperature ranges, $17 / 7,25 / 15$ and $30 / 20^{\circ} \mathrm{C}$, were chosen and germination trials were monitored for 31 days. These are typical seasonal day/night temperature ranges in the 
southern region of Australia in winter, spring and autumn, and summer.

The temperature germination trials were conducted under two light regimes, 12 hours light/12 hours dark and 24 hours dark, the first of which mimics the expected light conditions for seeds residing on the soil surface and the second a situation where seeds are buried in leaf litter or below the surface of the soil. To simulate 24 hours of darkness, Petri dishes were wrapped in aluminium foil. To maintain conditions of complete darkness for the entire trial period, whenever seeds from the 24 hours dark treatment were counted, Petri dishes were opened only under a green safe light.

The highest germination rates for each species occurred in different temperature ranges and under different light regimes; therefore each was chosen to give optimal results for the individual species under examination. For $V$. bromoides the highest germination occurred at $25 / 15^{\circ} \mathrm{C}$ and there was no significant difference between the 12 hours light/12 hours dark and 24 hours dark regimes. Therefore, the remainder of the trials for $V$. bromoides were conducted under the 12 hours light $/ 12$ hours dark regime at $25 / 15^{\circ} \mathrm{C}$. The highest germination of $V$. myuros was in 24 hours dark regime at $17 / 7^{\circ} \mathrm{C}$, so the remainder of the trials for this species were conducted under these conditions.

\section{Varying $\mathbf{p H}$}

Germination response of Vulpia spp. to varying soil $\mathrm{pH}$ was tested using a range of buffer solutions, with $\mathrm{pH}$ values of $4,5,6,8,9$, and 10 . All solutions were prepared according to the procedures described by Chachalis and Reddy (2000). The $\mathrm{pH}-4$ solution was prepared from a $2 \mathrm{mM}$ solution of potassium hydrogen phthalate (KHP), adjusted to $\mathrm{pH} 4$ with $1 \mathrm{~N}$ hydrochloric acid $(\mathrm{HCl})$. The $\mathrm{pH} 5$ and 6 solutions were prepared from $2 \mathrm{mM}$ solutions of MES [2-( $N$-morpholino) ethanesulfonic acid], adjusted to $\mathrm{pH} 5$ and 6 with $1 \mathrm{~N}$ sodium hydroxide $(\mathrm{NaOH})$. The $\mathrm{pH}$ 8 solution was prepared from a $2 \mathrm{mM}$ solution of HEPES [ $N$-(2-hydroxymethyl) piperazine$\mathrm{N}$-(2-ethanesulfonic acid)], adjusted to $\mathrm{pH} 8$ with $1 \mathrm{~N} \mathrm{NaOH}$. The pH 9 and 10 buffers were prepared from $2 \mathrm{mM}$ solutions of Tricine [ $\mathrm{N}$-Tris (hydroxymethyl) methylglycine], adjusted with 1 $\mathrm{N} \mathrm{NaOH}$ (Chachalis \& Reddy 2000).

\section{Salinity}

The effect of increasing salinity on the germination of Vulpia spp. was investigated using varying concentrations of sodium chloride $(\mathrm{NaCl})$ solution; $0,25,50,100,150,200$ and $250 \mathrm{mM}$. The control $(0 \mathrm{mM})$ was reverse osmosis $(\mathrm{RO})$ water and the remaining five concentrations are in the expected range of dissolved salts in fresh surface and ground irrigation waters (Anon. 2017).

\section{Moisture stress}

Response of Vulpia spp. to decreasing soil moisture availability was investigated by germinating seeds in solutions of five increasing osmotic potential, which were made from polyethylene glycol 8000 (PEG). These osmotic potentials were $-0.1,-0.2,-0.4,-0.6$ and $-0.8 \mathrm{MPa}$.

\section{Heat shock and smoke}

For the combined effects of heat and smoke on Vulpia spp., aluminium foil packets of seed were heat-treated in a laboratory oven (Memmert, Type No. ULE500) at temperatures of 40, 60, 80, 100 , and $120^{\circ} \mathrm{C}$. Six sets of 20 seeds were heattreated for 2 or 4 minutes. Seeds were cooled and placed into labelled plastic vials until the commencement of germination trials. The seeds were germinated either in sterilised $\mathrm{RO}$ water or in a $10 \%$ solution of smoke water (Regen ${ }^{\circledR} 2000$ smoke water), which was prepared with sterilised $\mathrm{RO}$ water.

\section{Burial depth}

Soil was collected from the areas where $V$. bromoides and V. myuros were observed to grow, in Skipton and Werribee. The soil was autoclaved to kill all seeds and other propagules. There were six replicates of 50 seeds of each species and the seeds were buried at six different depths, $0,0.5$, $1.0,2.0,3.0$ and $4.0 \mathrm{~cm}$. Rectangular black plastic trays $(10 \mathrm{~cm} \times 6 \mathrm{~cm} \times 6 \mathrm{~cm})$ were used, and the trays were lined with paper towels before the 
soil and seeds were added. Afterwards, the trays were placed in white 'butcher's trays' $(28 \mathrm{~cm} \mathrm{x}$ $44 \mathrm{~cm} \mathrm{x} 5.5 \mathrm{~cm}$ ), before water was added to the white trays. This enabled watering of the samples from below, ensuring minimal disturbance of the soil and seeds. The white trays were placed in germination cabinets and monitored regularly for seedling emergence.

\section{Statistical analyses}

For temperature and light regime, and $\mathrm{pH}$, the germination percentage $(G \%)$ and standard error (SE) were calculated from each set of six replicates.

For the effects of salinity, and heat and smoke, germination percentage values, $G \%$, were fitted to a three-parameter sigmoid model, $G(\%)=G_{\max }$ $/\left(1-\mathrm{e}^{\left(-\mathrm{x}-\mathrm{x}_{50}\right) / \mathrm{b}}\right)$, where $G \%$ is the total germination (\%) at concentration $x, G_{\max }$ is the maximum germination (\%), $x_{50}$ is the salt concentration or temperature for $50 \%$ inhibition of the maximum germination and $b$ indicates the slope of the graph.

Exponential decay curves were fitted to the osmotic potential and burial depth data, as $G(\%)$ $=G^{\star} e\left(-G^{*} x\right)$ or $E(\%)=E^{*} e\left(-E^{\star} x\right)$ respectively, where, $G(\%)$ or $E$ (\%) represents cumulative germination or emergence (\%) at time $x, G$ or $E$ is the maximum germination or emergence, and $-G$ or $-E$ indicates the slope.

Data were analysed using the SPSS software program. The P-value for each factor was calculated with a univariate ANOVA test, individually for each species.

\section{RESULTS}

\section{Light and temperature}

A significantly higher germination percentage overall was observed in V. bromoides ( $\sim 83 \%$ to $100 \%$ ) than V. myuros ( $65 \%$ to $98 \%$ ) (Figs. 1a $\&$ b), with $>80 \%$ germination for $V$. bromoides regardless of temperature or light treatment. Light and temperature were also significantly influential on germination of $V$. bromoides $(\mathrm{P}<0.001$, both light and temperature). For $V$. myuros, the lowest temperature range gave both the lowest and highest germination rates, but under contrasting light conditions. Germination in the $17 / 7^{\circ} \mathrm{C}$ temperature range was $65.0 \%$ in the periodic light treatment, but $97.5 \%$ in the 24 hour dark treatment. The effect of temperature on $V$. myuros was less significant $(\mathrm{P}=0.079)$ than that of light $(\mathrm{P}<0.001)$.

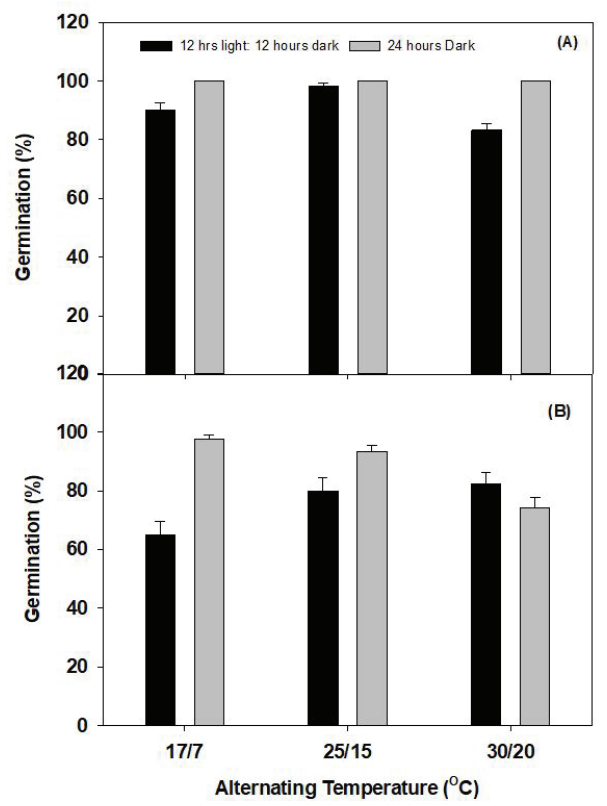

Figure 1 Germination of: (a) V. bromoides; and (b) V. myuros at three varying temperature ranges $\left(17 / 7,25 / 15\right.$ and $\left.30 / 20^{\circ} \mathrm{C}\right)$, representing winter, spring/autumn, and summer seasonal variations, and two light regimes, 12-h light/12-h dark and 24-h dark. Capped bars represent + standard errors of the means.

\section{Varying $\mathbf{p H}$}

The overall percentage of germination was $>85 \%$ for $V$. bromoides at each $\mathrm{pH}$ value (Fig. 2a) under the culture conditions used, i.e. 12 hours light/12 hours dark regime at $25 / 15^{\circ} \mathrm{C}$. The maximum and minimum germination for $\mathrm{V}$. bromoides was $93.3 \%$ at $\mathrm{pH} 10$ and $86.7 \%$ at $\mathrm{pH}$ 8. The overall percentage of germination was also $>85 \%$ for $V$. myuros at each $\mathrm{pH}$ value (Fig. 2b) under the culture conditions used, i.e. $24-\mathrm{h}$ dark at $17 / 7^{\circ} \mathrm{C}$. 
The maximum and minimum germination for $V$. myuros was $99.2 \%$ at $\mathrm{pH} 6$ and $87.5 \%$ at $\mathrm{pH} 5$. Change in $\mathrm{pH}$ was not significant for germination of $V$. bromoides $(\mathrm{P}=0.293)$, but was for $V$. myuros $(\mathrm{P}=0.016)$
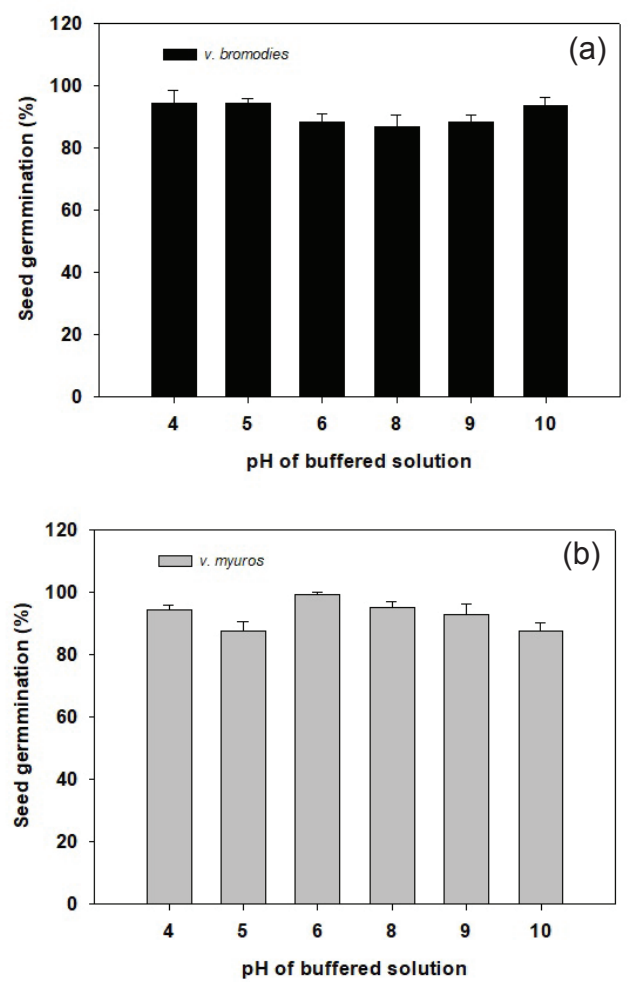

Figure 2 Germination of: (a) V. bromoides (black bars); and (b) V. myuros (grey bars) at six different $\mathrm{pH}$ values 4, 5, 6, 8, 9 10. Capped bars represent + standard errors of the means.

\section{Salinity}

Increasing salinity reduced germination for $V$. bromoides grown using 12 hours light/12 hours dark regime at $25 / 15^{\circ} \mathrm{C}$. The concentration of $\mathrm{NaCl}$ that reduced germination of $V$. bromoides by $50 \%$ of the maximum (93.3\%) was $138 \mathrm{mM}$ (Fig. 3a).

Increasing salinity also reduced germination for $V$. myuros grown in the dark at $17 / 7^{\circ} \mathrm{C}$. The concentration of $\mathrm{NaCl}$ that reduced germination of V. myuros by $50 \%$ of the maximum (97.5\%) was $159 \mathrm{mM}$ (Fig. 3b). Increasing salinity significantly reduced germination in both species ( $\mathrm{P}<0.001$, both species).
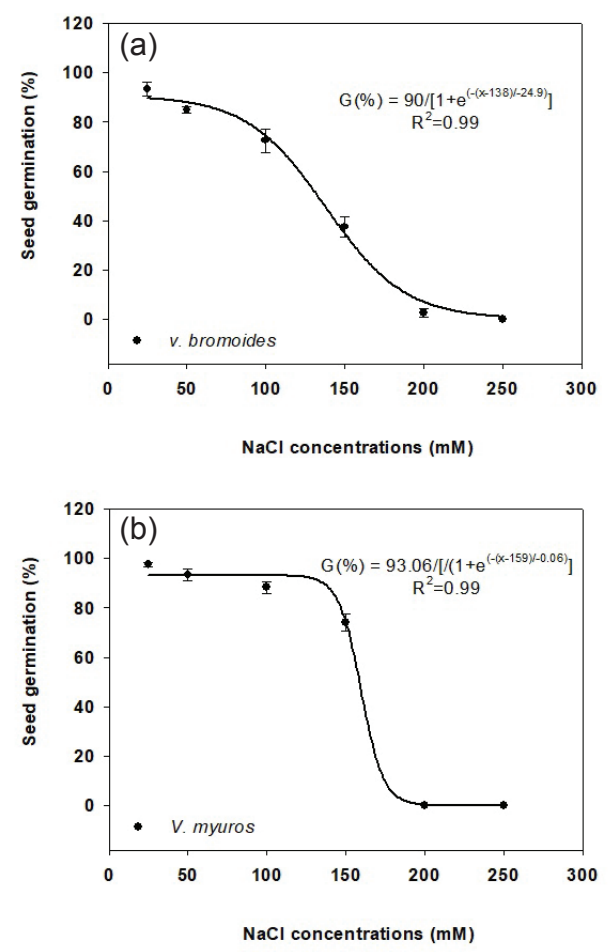

Figure 3 Germination of: (a) V. bromoides (black dot); and (b) V. myuros (white dot) at six different concentrations of $\mathrm{NaCl} ; 25,50,100,150,200$ and $250 \mathrm{mM}$. Capped bars represent + standard errors of the means.

\section{Moisture stress}

Each species was significantly affected overall by a reduction in the availability of moisture $(\mathrm{P}<0.05)$, although neither varied significantly in their response at low moisture stress (Figs. 4a \& b) $(\mathrm{P}=0.359)$. Germination was greater than $80 \%$ for both species at -0.1 and $-0.2 \mathrm{M}$ Pa despite the different culture conditions used. However, germination was significantly reduced in both species as moisture stress increased to -0.4 $\mathrm{MPa}$. Germination of both species was reduced to $0 \%$ at $-0.8 \mathrm{MPa}$. Increasing moisture stress significantly reduced germination $(\mathrm{P}<0.001$, both species). 



Figure 4 Germination of: (a) V. bromoides; and (b) V. myuros at six different osmotic potential concentrations; $-0.1,-0.2,-0.4,-0.6$, and -0.8 $\mathrm{MPa}$. Capped bars represent + standard errors of the means.

\section{Heat and smoke}

Germination of $V$. bromoides was nearly 100\% for seeds exposed heat-shock temperatures up to $80^{\circ} \mathrm{C}$ for either 2 or 4 minutes followed by germination in $\mathrm{RO}$ water using a 12-h light/12-h dark regime at $25 / 15^{\circ} \mathrm{C}$. Thereafter, germination in RO water declined significantly and was reduced to approximately $20 \%$ at $120^{\circ} \mathrm{C}$. The temperature that induced a $50 \%$ reduction in the maximum germination was approximately $105^{\circ} \mathrm{C}$ (Fig. 5a). Use of smoke water instead of RO water to culture $V$. bromoides reduced germination to less than $80 \%$ for seeds exposed heat-shock temperatures up to $80^{\circ} \mathrm{C}$. The temperature that induced a 50\% reduction in the maximum germination was approximately $91^{\circ} \mathrm{C}$ (Fig. 5b) for a combination of smoke and heat shock. Time of exposure to heat did not significantly affect germination $(\mathrm{P}=0.251)$, but increase in temperature combined with exposure smoke did significantly reduce germination $(\mathrm{P}<0.001)$. The interaction of increased temperature and smoke also had a more significant effect on germination $(\mathrm{P}<0.001)$ than the either of the interactions of time and temperature $(\mathrm{P}=0.418)$ or time and smoke $(\mathrm{P}=0.109)$.
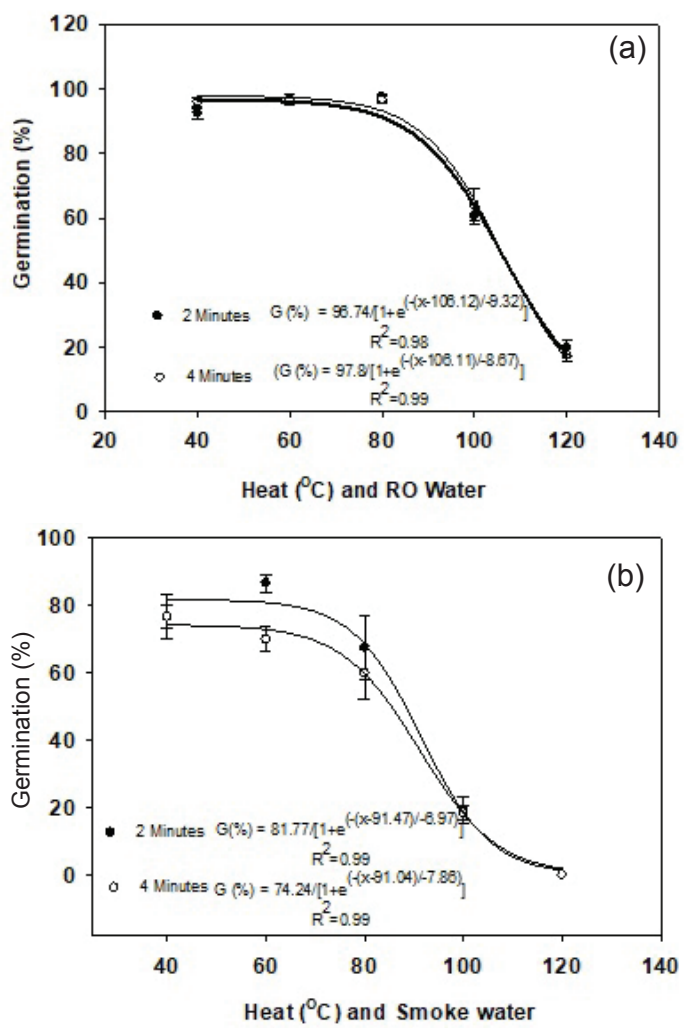

Figure 5 Germination of $V$. bromoides following heat treatment of seeds for 2 (black dots) and 4 (white dots) minutes in: (a) RO water; and (b) $10 \%$ smoke water. Capped bars represent + standard errors of the means. 
For $V$. myuros, there was no significant reduction in germination of seeds exposed to heat shock at any temperature or time prior to culture with $\mathrm{RO}$ water in the dark at $17 / 7^{\circ} \mathrm{C}$. (Fig. 6a). However, subsequent culture in the dark at $17 / 7^{\circ} \mathrm{C}$ using smoke water instead of $\mathrm{RO}$ water significantly reduced germination in seeds previously exposed to $120^{\circ} \mathrm{C}(\mathrm{P}<0.05)$. In this treatment, the temperatures that induced a $50 \%$ reduction of the maximum germination varied according to the length of heat exposure time, and were $123^{\circ} \mathrm{C}$ for 2 minutes and $117^{\circ} \mathrm{C}$ for 4 minutes (Fig. 6b). Time of heat exposure was not statistically significant $(\mathrm{P}=0.291)$, nor was the interaction of temperature and smoke $(\mathrm{P}=0.345)$. However, the interactions of time and increasing temperature $(\mathrm{P}=0.002)$ and time and
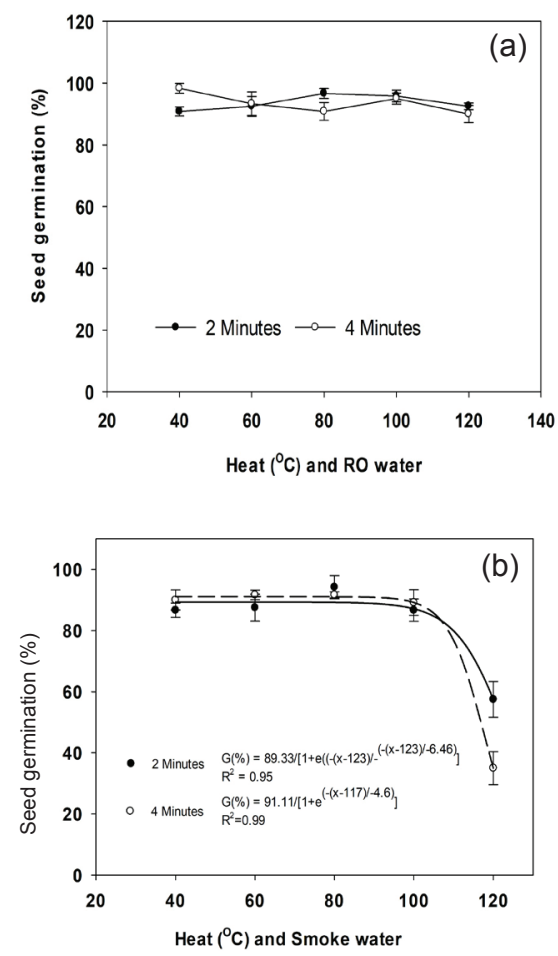

Figure 6 Germination of $V$. myuros following heat treatment of seeds for 2 and 4 minutes in: (a) $\mathrm{RO}$ water (black dotss $=2$ minutes, white dots $=4$ minutes); and (b) $10 \%$ smoke water (black dots = 2 minutes, white dots $=4$ minutes). Capped bars represent + standard errors of the means. smoke exposure $(\mathrm{P}<0.001)$ significantly reduced germination.

\section{Burial depth}

There was a significant reduction in germination with increasing burial depth $(\mathrm{P}<0.05)$ for $V$. bromoides (Fig. 7a) with maximum emergence (91.3\%) occurring in seeds placed on the soil surface $(0 \mathrm{~cm})$ and grown using a 12-h light/12-h dark regime at $25 / 15^{\circ} \mathrm{C}$. There was also significant reduction in germination with increasing burial depth $(\mathrm{P}<0.05)$ for V. myuros (Fig. 7b) grown in the dark at $17 / 7^{\circ} \mathrm{C}$ with maximum emergence (85.3\%) occurring in seeds placed on the soil surface $(0 \mathrm{~cm})$. Emergence was significantly reduced with increasing burial depth $(\mathrm{P}<0.001$, both species).

\section{DISCUSSION}
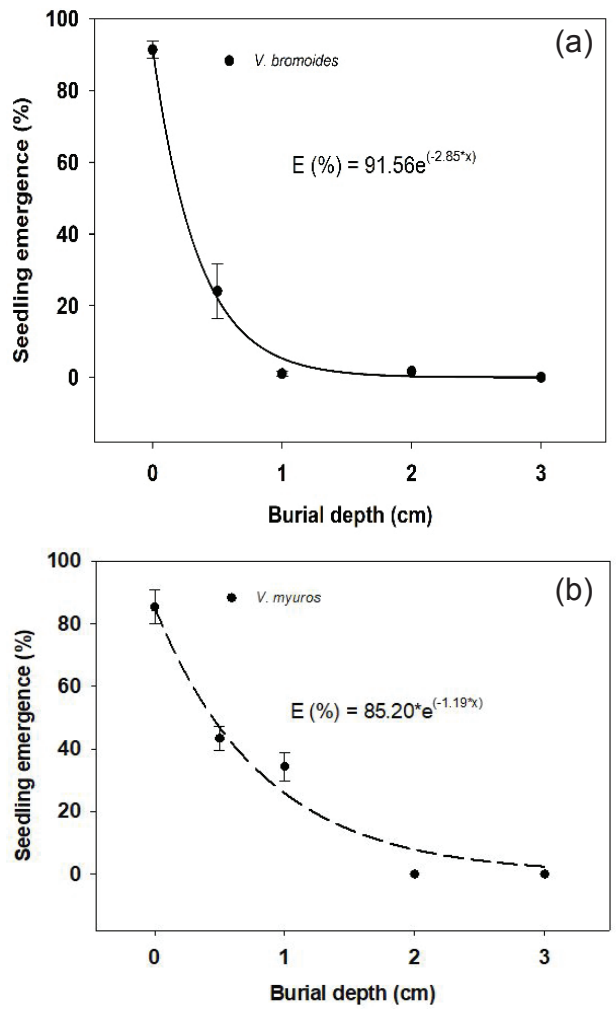

Figure 7 Burial depth of: (a) V. bromoides; and (b) $V$. myuros, at depths of $0,0.5,1.0,2.0,3.0$ and 4.0 $\mathrm{cm}$. Capped bars represent + standard errors of the means. 
Seed germination was $>65 \%$ for $V$. bromoides and $V$. myuros regardless of temperature. The temperature ranges within which both species germinated were consistent with the findings of other researchers in Australia (Flood \& Halloran 1982, Dillon \& Forcella 1984), the United States (Peart 1989, Hobbs \& Mooney 1986), Canada (Allcock 2002), and Chile (Figueroa et al. 2004). Dillion and Forcella (1984) determined that the temperature ranges of optimum germination for both species overlapped, but the minimum and maximum were slightly higher for $V$. myuros $\left(12-31^{\circ} \mathrm{C}\right)$ than for $V$. bromoides $\left(9-28^{\circ} \mathrm{C}\right)$ (Dillon \& Forcella 1984). Similar findings were obtained in the current study when a light /dark culture regime was used. These temperature ranges are also similar to those required for the germination of many other members of native and introduced members of Poaceae (Cocks \& Donald 1973, Baskin \& Baskin 1981, Maze et al. 1993, Chejara et al. 2008, Fernando et al. 2016). This is likely due to similarities of climate within the native ranges of these grasses, and indicates a strong possibility for persistence of these species within the Mediterranean climate region of Australia.

An absence of light did not affect germination of $V$. bromoides, since germination of this species in all three temperature ranges in the 24-h dark treatment was $100 \%$. However, $V$. myuros appeared to be affected by a combination of temperature and alternating light, since germination increased in the 12-h light/12-h dark treatment, with increasing temperature, but was reduced in the 24-h dark treatment with increasing temperature. This finding contrasts with those of Dillon and Forcella who concluded that an absence of light did not inhibit germination of $V$. myuros (Dillon \& Forcella 1984). Therefore, temperature may be a stricter requirement for germination than the availability of light for $V$. myuros. Germination of other Poaceae species is also influenced by alternating light and dark or complete darkness, for example, Chloris truncata and Chloris virgata germinate more readily in 12-h light/12-h dark than 24 -h dark (Ngo et al. 2014). Different species of $\mathrm{C}_{3}$ grasses also vary in their response to light exposure during germination; Eragrostis curvula is seen to be inhibited whereas Elymus scabrus is not (Maze et al. 1993).

Germination of both species was very high at a range of $\mathrm{pH}$ values, indicating that both have a tolerance for a wide range of soil types. However, field observations from Europe, England and Australia indicate these species more commonly occur on slightly acid soils. For example, Vacher (1984) noted that, in its native range, V. myuros occurs on volcanic and slightly acid soils (Vacher 1984). This is supported by the findings of Smith and Clarke (1991), who noted that V. bromoides grew more readily in soil collected from an abandoned agricultural field in which the soil $\mathrm{pH}$ (5.64) was less acidic than an adjoining field (4.82) (Smith \& Clarke 1991). Australian researchers investigating the management of acid soils in agriculture, listed $V$. bromoides among a range of common weeds that are associated with acid soils (Scott et al. 2000). However, the findings of the current study appear to exclude the possibility that alkaline soils would inhibit germination of either species. It is possible that both species may become established in regions where the soil type varies significantly from their native ranges. Further investigation of this likelihood is recommended - specifically the effects of alkaline soils on plant establishment and maturation.

Increasing salinity reduced germination in both species and highly saline soils may inhibit establishment of both species. However, further investigation at the effect of growth subsequent to germination on the development of plants to maturity and seed production is needed to confirm this finding. It has been reported that another effect of saline conditions is to delay, as well as reduce, the germination of grasses (Taleisnik et al. 1997).

Both species germinated well (generally $>70 \%$ ) at an osmotic potential $-0.4 \mathrm{MPa}$ or above $(-0.2$ and $0 \mathrm{MPa})$, but germination declined significantly at $-0.6 \mathrm{MPa}$ and lower. Both species display a typical response for $\mathrm{C}_{3}$ grasses, which are cool-season annual grasses, that are hypothesised to require more moisture for 
germination (e.g. Danthonia caespitosa) than $\mathrm{C}_{4}$ (warm season perennial) grasses (e.g. Bothrichloa macra) (Maze et al. 1993). Previous research has indicated that $V$. bromoides and $V$. myuros show a tolerance for a wide range of conditions, from fairly wet though to dry soils in their native range (Volaire et al. 1991), although neither species is completely drought tolerant (Dillon \& Forcella 1984, Wallace 1997). Indeed, drought can reduce Vulpia spp. recruitment levels, although this may be only temporary and recovery from the soil seed bank is possible if this type of event is not excessively prolonged (Brown \& Rice 2000).

Germination of Vulpia bromoides seeds in RO water using a 12-h light/12-h dark regime at $25 / 15^{\circ} \mathrm{C}$ was significantly inhibited by preplanting heat shock. However, germination of V. myuros seeds in the dark at $17 / 7^{\circ} \mathrm{C}$ was not affected by pre-planting heat shock. Smoke water had an additional effect on reducing germination of both species, but in V. myuros this occurred only in seeds previously exposed to the highest temperature of $120^{\circ} \mathrm{C}$. Other Poaceae species show a similar tolerance for heat; for example, germination of C. virgata is reduced to $50 \%$ of the maximum after pre-germination heat treatment at $119^{\circ} \mathrm{C}$ (Fernando et al. 2016), which is a higher than that which affected $V$. bromoides whereas $V$. myuros was unaffected at this temperature (Fig. $5 \mathrm{a})$. The different of each species to heat and smoke indicates, perhaps, that $V$. myuros may be better adapted to fire than $V$. bromoides. However, field studies of the effect of fire on grasslands that contain infestations of these species demonstrate an increase in cover of this grass weed following the fire event (Lunt 1990, Figueroa et al. 2009, Figueroa \& Cavieres 2012). It is thought that the response of $V$. bromoides is not due to the vulnerability of its seeds to heat. Instead, any seeds present in the soil seed bank, which are not exposed to direct heat, are be available to germinate in the gaps left by the removal of other species as a result of the fire (Tozer et al. 2008).

Both species germinated readily on the soil surface under the culture conditions used for each species. No seedlings of either species emerged from 2 or $3 \mathrm{~cm}$, however. Small seeded grasses, such as $V$. bromoides and $V$. myuros, do not possess large energy stores and so are unlikely to either form long-lasting soil seed banks or be able to emerge from depths of greater than a few centimetres at most (Fenner \& Thompson 2005). For example, germination of other Vulpia species, e.g. V. membranacea, is also favoured with seed placement on the soil surface, but significantly reduced at relatively shallow burial depths (Pemadasa \& Lovell 1975). Vulpia spp. and other small seeded grasses are likely to be a problem in no-till farming systems, especially if areas of bare soil are present to aid recruitment (Tozer et al. 2008).

It is apparent that both these species establish more readily during the cooler and wetter times of year, since each is termed a 'winter annual' grass (Ball et al. 1980, McGowan, 1970), in late autumn and early winter, thereby potentially excluding the establishment of more palatable pasture grass species that typically germinate and establish during spring and summer. There is also a possibility that either or both species could establish on soil types with a wide $\mathrm{pH}$ range, provided that adequate moisture and suitably low salinity are present. Vulpia myuros may be more likely to establish in slightly more saline and drier situations than $V$. bromoides, but this difference is not significant. Fire may be useful to control $V$. bromoides by the removal of above-ground biomass and seed heads, but additional measures must be applied, for example pasture renovation techniques, to prevent re-establishment of the species from the soil seedbank. Cultivation of pastures prior to the addition of fertiliser and seed would allow the establishment of competitive grass and legume species that can exclude reestablishment of Vulpia spp. Fire may not reduce $V$. myuros as successfully as $V$. bromoides but, nevertheless, the same approach of pasture renovation may be useful after fire. Additionally, seeds of either species remaining on the surface in areas set apart for no-till crops may interfere with production of grain crops, suggesting that tillage should be used to bury seeds to prevent germination. However, consideration for the timing of these measures to successfully replace 
these two Vulpia species is necessary. For example, autumn burning to remove plant biomass and kill seeds in the soil, followed immediately by pasture renovation with rapidly germinating grasses may lead to successful re-establishment of pastures more quickly than if these approaches are applied during spring or summer. Alternatively, or according to climatic region, the opposite may be the case. We suggest that further research into establishing which time of year these methods might succeed in each region where these species occur, be conducted.

Both of these weeds show the typical responses of annual cool-season ( $\left.\mathrm{C}_{3}\right)$ grasses, indicating that they can establish in regions with sufficiently low winter temperatures and cool season rainfall. Such conditions are typical of much of the grazing and cropping regions of southern Australia. This observation raises an important question: of how will these species respond to possible changes to temperature and rainfall patterns and increases in atmospheric carbon dioxide (IPCC 2014) in the future? We recommend tilling of soil to prevent germination of $V$. bromoides and $V$. myuros in cropping situations, and the use of fire followed by pasture renovation in grazing pastures to address infestations of these weeds. Also, we suggest that future work should concentrate on the effects of elevated carbon dioxide levels on these species. This factor was not investigated in this study, but has caused increased resistance to herbicides in other weed species (Fernando et al. 2016). If elevated carbon dioxide levels do change herbicide resistance in these two weed species, current approaches for management of these weeds would need to be reconsidered.

\section{ACKNOWLEDGEMENTS}

We wish to thank Wendy Cloke for providing technical support and the Faculty of Science and Technology, Federation University Australia for making available its science facilities, without which this project would not been possible.

\section{REFERENCES}

Ainscough MM, Barker CM, Stace CA 1986. Natural hybrids between Festuca and species of Vulpia section Vulpia. Watsonia 16: 143151.

Alfonso Y 2010a. Austgrass2 Fact Sheet: Vulpia bromoides. http://ausgrass2.myspecies.info/ content/vulpia-bromoides. (Accessed: 29 July 2017).

Alfonso Y 2010b. Austgrass2 Fact Sheet: Vulpia myuros. http://ausgrass2.myspecies.info/ content/vulpia-myuros. (Accessed: 29 July 2017).

Allcock KG 2002. Effects of phosphorus on growth and competitive interactions of native and introduced species found in White Box woodlands. Austral Ecology 27: 638-646.

Anon 2017. Electrical Conductivity Meters. http://www.dwc-water.com/technologies/ others/water-quality-tester/index.html. (Accessed: 7 September 2017).

Ball DA, Frost SM, Fandrich L, Tarasoff C, Mallory-Smith C 2008. Biological attributes of rattail fescue (Vulpia myuros). Weed Science 56: 26-31.

Baskin JM, Baskin CC 1981. Ecology of germination and flowering in the weedy winter annual grass Bromus japonicus. Journal of Range Management 34: 369-372.

Brown CS, Rice KJ 2000. The mark of Zorro: Effects of exotic annual grass Vulpia myuros on California native perennial grasses. Restoration Ecology 8: 10-17.

Chachalis D, Reddy KN 2000. Factors affecting Campsis radicans seed germination and seedling emergence. Weed Science 48: 212216.

Chejara VK, Kristiansen P, Whalley RDB, Sindel BM, Nadolny C 2008. Factors affecting germination of Coolatai grass (Hyparrhenia hirta). Weed Science 56: 543-548.

Clarke S, French K 2005. Germination response to heat and smoke of 22 Poaceae species from grassy woodlands. Australian Journal of Botany 53: 445-454.

Cocks PS, Donald CM 1973. The germination and establishment of two annual pasture grasses (Hordeum leporinum Link and 
Lolium rigidum Gaud.). Australian Journal of Agricultural Research 24: 1-10.

Connor HE 1998. Breeding systems in New Zealand grasses XII. Cleistogamy in Festuca. New Zealand Journal of Botany 36: 471-476.

Dillon SP, Forcella F 1984. Germination, emergence, vegetative growth and flowering of two silvergrasses, Vulpia bromoides (L.) S.F. Gray and V. myuros (L.) C.C. Gmel. Australian Journal of Botany 32: 165-175.

Dowling PM 1996. The ecology of Vulpia. Plant Protection Quarterly 11: 204-206.

Dowling PM, Leys AR, Verbeek B, Millar GD, Lemerle D, Nicol HI 2004. Effect of annual pasture composition, plant density, soil fertility and drought on vulpia (Vulpia bromoides (L.) S.F. Gray). Australian Journal of Agricultural Research 55: 1097-1107.

Fenner M, Thompson K 2005. The Ecology of Seeds. Cambridge University Press, Cambridge, UK. 260 p.

Fernando N, Humphries T, Florentine SK, Chauhan BS 2016. Factors affecting seed germination of feather fingergrass (Chloris virgata). Weed Science 64: 605-612.

Fernando N, Manalil S, Florentine SK, Chauhan BS, Seneweera S 2016. Glyphosate resistance of $\mathrm{C}_{3}$ and $\mathrm{C}_{4}$ weeds under rising atmospheric $\mathrm{CO}_{2}$. Frontiers in Plant Science 7: 1-11.

Figueroa JA, Teillier S, Jaksic FM 2004. Composition, size and dynamics of the seed bank in a Mediterranean shrubland of Chile. Austral Ecology 29: 574-584.

Figueroa JA, Cavieres LA, Gomez-Gonzalez S, Montenegro MM, Jaksic FM 2009. Do heat and smoke increase emergence of exotic and native plants in the matorral of central Chile? Acta Oecologica 35: 335-340.

Figueroa JA, Cavieres LA 2012. The effect of heat and smoke on the emergence of exotic and native seedlings in a Mediterranean fire-free matorral of central Chile. Revista Chilena de Historia Natural 85: 101-111.

Flood RG, Halloran GM 1982. Flowering behaviour of four annual grass species in relation to temperature and photoperiod. Annals of Botany 49: 469-475.
Hobbs RJ, Mooney HA 1986. Community changes following shrub invasion of grassland. Oecologia 70: 508-513.

IPCC 2014. Climate Change 2014: Synthesis Report. (Ed: Pachauri RK, Meyer LA). IPCC, Geneva, Switzerland. 151 p. https://www. ipcc.ch/pdf/assessment-report/ar5/syr/SYR_ AR5_FINAL_full_wcover.pdf (Accessed 24 September 2018).

Kloot PM 1982. The naturalization of Echium plantagineum L. in Australia. Australian Weeds (Australia) 1: 29-31.

Loo C 2005. The ecology of naturalised silvergrass (Vulpia) populations in south-western Australia. PhD Thesis, Faculty of Natural and Agricultural Sciences, University of Western Australia, Perth, Western Australia. 150 p.

Lunt ID 1990. Impact of an autumn fire on long-grazed Themeda triandra. Victorian Naturalist 107: 45-51.

Matthews J 2000. Silvergrass in the upper southeast. PIRSA Crop Harvest Report 1999-2000. PIRSA, Adelaide, South Australia.

Maze KM, Koen TB, Watt LA 1993. Factors influencing the germination of six perennial grasses of central New South Wales. Australian Journal of Botany 41: 79-90.

McGowan AA 1970. Comparative germination patterns of annual grasses in north-eastern Victoria. Australian Journal of Experimental Agriculture 10: 401-404.

McIntyre S, Whalley RDB 1990. Co-occurrence of Vulpia species on the northern tablelands of New South Wales. Australian Journal of Botany 38: 445-450.

Ngo TD, Boutsalis P, Preston C, Gill G 2014. Seed biology of Chloris truncata (windmill grass) and Chloris virgata (feathertop Rhodes grass). In: 19th Australian Weeds Conference (Baker M ed.) pp. 75-78. Tasmanian Weed Society, Hotel Grand Chancellor, Hobart, Tasmania, Australia.

Peart DR 1989. Species interactions in a successional grassland. I. Seed rain and seedling recruitment. Journal of Ecology 77: 236-251.

Pemadasa MA, Lovell PH 1975. Factors 
controlling germination of some dune annuals. The Journal of Ecology 63: 41-59.

Popay I 2017. Fact sheet: Vulpia bromoides (squirreltail fescue). CAB International, Wallingford, UK. https://www.cabi.org/isc/ datasheet/117873. (Accessed 29 July 2017).

Scott BJ, Ridley AM, Conyers MK 2000. Management of soil acidity in long-term pastures of south-eastern Australia: a review. Australian Journal of Experimental Agriculture 40: 1173-1198.

Simon BK (2010) Austgrass2 Fact Sheet: Vulpia. http://ausgrass2.myspecies.info/content/ vulpia-0. (Accessed: 29 July 2017).

Smith REN, Webb NR, Clarke RT 1991. The establishment of heathland on old fields in Dorset, England. Biological Conservation 57: 221-234.

Taleisnik E. Peyrano G, Arias C 1997. Response of Chloris gayana cultivars to salinity. 1 . Germination and early vegetative growth. Tropical Grasslands 31: 232-240.

Tozer, K 2004. Ecology and management of Vulpia spp. G. C. Gmelin in perennial pastures of southern Australia. PhD Thesis, Institute of Land and Food Resources, University of Melbourne, Melbourne, Australia. 234 p.

Tozer KN, Chapman DF, Quigley PE, Dowling PM, Cousens RD, Kearney GA 2008. Effect of grazing, gap dynamics, and inter-specific seedling competition on growth and survival of Vulpia spp. and Hordeum murinum ssp. leporinum. Australian Journal of Agricultural Research 59: 646-655.

Vacher J 1984. Phyto and agro-ecological analysis of the pastoral dehesas of the Sierra Norte (Western Andalusia, Spain). Centre National de la Recherche Scientifique. 195p.

Vere DT, Jones RE, Dowling PM, Kemp DR 2002. Economic impact of Vulpia in temperate pasture systems in south-eastern Australia. Australian Journal of Experimental Agriculture 42: 465-472.

Vere DT, Jones RE, Griffith GR 2003. Economic benefits of public investment in weed management: the case of vulpia in southeastern Australia's temperate pasture areas.
Australian Journal of Agricultural and Resource Economics 47: 519-539.

Vere DT, Jones RE, Dowling P 2004. An economic evaluation of research into the improved management of the annual grass weed vulpia in temperate pastures in south-eastern Australia. NSW Department of Primary Industries, Orange, New South Wales. p. 30.

Volaire F, Lelievre F, Godron M 1991. Distribution of main grass and legume species in native grasslands of Corsica. New Zealand Journal of Botany 121: 251-262.

Wallace A 1997. The biology of Australian weeds. 30. Vulpia bromoides ((L.) SF Gray) and $V$. myuros ((L.) CC Gmelin). Plant Protection Quarterly 12: 18-28.

Weber E 2017. Fact sheet: Vulpia myuros (annual fescue). CAB International, Wallingford, UK. https://www.cabi.org/isc/datasheet/117880. (Accessed 28 July 2017). 